\title{
Inflation Problem
}

National Cancer Institute

\section{Source}

National Cancer Institute. Inflation Problem. NCI Thesaurus. Code C63076.

Problem associated with the inability of the device to expand or enlarge with the intended inflation agent (e.g. saline or air). 